\title{
A Logical Approach to Supporting Professional Learning Communities
}

\author{
Laurie F. Ruberg*
}

Center for Educational Technologies

Wheeling Jesuit University, USA

E-mail: lruberg@cet.edu

\section{Meri Cummings}

Center for Educational Technologies

Wheeling Jesuit University, USA

E-mail: meri@cet.edu

\section{Debra C. B. Piecka}

Center for Educational Technologies

Wheeling Jesuit University, USA

E-mail: dpiecka@cet.edu

\section{Chris Ruckman}

Center for Educational Technologies Wheeling Jesuit University, USA

E-mail: ruckman@cet.edu

\section{Ralph Seward}

Center for Educational Technologies

Wheeling Jesuit University, USA

E-mail: rjseward@cet.edu

*Corresponding author

\begin{abstract}
Collaborative knowledge sharing requires that dialogues successfully cross organizational barriers and information silos. Successful communication in person or in a virtual community involves a willingness to share ideas and consider diverse viewpoints. This research examines a science, technology, engineering, and mathematics (STEM) content management system called NASATalk, which offers public and private blog posts, file sharing, asynchronous discussion, and live chat services. The service is designed to provide a virtual environment where educators can share ideas, suggestions, successes, and innovations in STEM teaching and learning activities. This study features qualitative data from STEM education groups that helped extend the design of the NASATalk Web 2.0 collaborative tools and features. The analysis shows that the context, e-collaborative tools, integration strategies, and outcomes varied, but also contributed additional space, time,
\end{abstract}


tools, integration strategies, and outcomes through the virtual collaborative learning environment. This study is designed to inform the STEM education community as well as those offering virtual community resources and tools of the added value of using virtual communities to help STEM educators work together in collaborative, virtual environments to discuss ways they can improve their instruction and student performance.

Keywords: Virtual Collaboration; STEM Education; Knowledge Sharing; Virtual Professional Development; E-Collaborative Tools; Virtual STEM Collaborative Communities

Biographical notes: Laurie Ruberg received her Ph.D. in curriculum and instruction from Virginia Tech. She is the associate director and senior instructional designer at the Center for Educational Technologies at Wheeling Jesuit University. She serves as project manager for the NASATalk web-based collaborative and is an active blogger and researcher at this website (www.nasatalk.com). Her research interests include problem-based learning instructional design for climate science issues and program evaluation, specializing in STEM education and health and safety research projects. Ruberg has received several awards for her design and evaluation work.

Meri Cummings is a science curriculum writer and resource teacher at the Center for Educational Technologies. She earned her Ph.D. in biological oceanography from the University of Miami. She has designed a number of LEGO robotics challenges and assessments to help educators and students learn robotics building and programming, and she runs a series of NXT robotics collaborative groups and blogs on NASATalk. Cummings mentors Girl Scout robotics teams, teaches WaterBotics, and directs the West Virginia FIRST LEGO League robotics competition.

Debra C. Burkey Piecka is an educational researcher and instructional designer at the Center for Educational Technologies. She received her Ed.D. in instructional technology from Duquesne University. Her research interests focus on collaboration in online communities and evaluation of distance-based simulations.

Chris Ruckman is a computer programmer at the Center for Educational Technologies. A Wheeling Jesuit University alumnus with a bachelor's degree in computer science, he has worked in professional desktop and web-based application development and is developing new websites for the Exploring the Environment-Global Climate Change and CyberSurgeons programs.

Ralph Seward is a programmer, data analyst, and website technician at the Center for Educational Technologies. He is a graduate of Wheeling Jesuit University, where he currently sits on the university's mission and identity team.

\section{Introduction}

Collaborative knowledge sharing requires that people understand each other. In the workplace dialogue must successfully cross organizational barriers and information silos. Successful communication in person or in a virtual community involves a willingness to share ideas and consider diverse viewpoints. Communication includes more than a presentation of facts. Knowledge sharing is bundled with disclosure of attitudes and values. Ultimately, once received and interpreted, communication results in consequences, 
impacts, and outcomes. Our research examines a science, technology, engineering, and mathematics (STEM) content management system (CMS) called, NASATalk, which offers public and private blog posts, file sharing, asynchronous discussion, and live chat services. The service is designed to provide a virtual environment where educators can share ideas, suggestions, successes, and frustrations about their STEM teaching and learning activities. This study addresses the need for greater understanding about how to effectively use online contexts to enhance and expand opportunities for professional development through effective use of virtual learning communities (VLC).

NASATalk uses the Joomla content management system, which enables a variety of online web services to support collaborative, interactive communities within and across our targeted communities of people involved in STEM education initiatives. Several features of Joomla made it appealing and particularly appropriate for this project, including its ease of use, expandability, and minimal cost as an open source application. NASATalk targets formal and informal educators, scientists, engineers, and technologists involved in efforts to reform and advance STEM learning for elementary through high school youth. It features blog postings, community areas, resource announcements, and calls for participation.

The NASATalk collaborative web portal was established to provide an easy-touse virtual space where teachers can freely share their ideas about ways to improve student learning in STEM subjects. Successful STEM education provides students with science, technology, engineering, and mathematics in sequenced lessons that build upon each other and can be used with real world applications. Successful STEM education creates critical thinkers, increases science literacy, and enables the next generation of innovators. Most jobs of the future will require a basic understanding of math and science-10-year employment projections by the U.S. Department of Labor show that of the 20 fastest growing occupations projected for 2014, significant mathematics or science preparation are required for 15 of them. Improving student achievement in STEM areas is a national priority in the United States. Especially with STEM education described as a national crisis and with improving student performance in STEM subjects considered a national priority, teachers need community support where they can share ideas, concerns, and reflections on their classroom practices. The goal of the NASATalk collaborative website is to give teachers tools, strategies, and a safe virtual social context where they can freely discuss STEM reform and improvement efforts-both those they are part of and those about which they want to know more.

NASATalk was established as a spinoff of a benchmarking study that examined how technology experts and educators were using media tools to enhance their research and instructional practices. The study (Howard \& Tomei, 2008; Ruberg, Calinger, \& Howard, 2008) resulted in an interactive online environment that could inform and encourage wider adoption of the innovative practices outlined in the report. A growing component of teacher professional development and curriculum reform involves the inclusion of online services for support, interaction, and expanded content. In this paper we examine the e-collaborative tools and strategies the NASATalk CMS has used to facilitate and support a variety of STEM education professional learning communities.

\subsection{Transforming Project Activities into Virtual Collaboration Opportunities}

This research draws examples from STEM projects that have used this CMS service to illustrate how e-collaborative tools and integration strategies helped participants reach 
their communication goals. In the examples cited, the online collaborative groups involved STEM education topics, but the context for the examples differed greatly. As curriculum developers, instructional designers, programmers, and program evaluators, we initiated this research to find out how to apply e-collaborative tools and integration strategies to better serve our CMS STEM education professional project groups. Our goal was to help transform project activities into virtual opportunities for community development and enhanced communication.

\subsection{Participant Culture and Community Contexts}

The participants in each of the virtual communities referenced in the examples cited were self-motivated to join these online collaborative groups based on their areas of interest and personal and professional affiliations. The logic model presented in Figure 1 represents the key components examined in this qualitative study of virtual communities. The virtual collaborative groups are first examined as a dynamic CONTEXT that includes its own power structures and dynamics, organizational systems and procedures, domain knowledge systems, and culture and community. The participants in each collaborative community are approached as active agents in this four-tiered social context. Components of the context analysis build off work by Cheuk and Dervin (2011) in which they propose how to make Web 2.0 achieve what it promises to offer to support virtual collaboration. Continuing to use the logic model provided in Figure 1 as the guide, the next lens for NASATalk CMS analysis examines how different virtual communities use each of the e-collaborative tools. The INTEGRATION STRATEGIES column in the logic model suggests that online community dialogues should be reviewed to determine whether one or more of the four social mediation strategies was used to support and guide the virtual community interactions. The fourth and final column of the logic model identified areas for possible outcomes that can be expected as OUTCOMES of participation in one of the virtual CMS collaborative groups.

Across all three cases the primary audiences participating in each collaborative VLC were STEM educators. This is a broad field and encompasses a wide range of expertise and qualifications. Here is a brief overview of how the audiences in the three example groups (referred to as Case 1,2, and 3) differed. Participants in Case 1 had a strong technology background and were accustomed to integrating science and engineering activities into their classroom teaching. About half of this group came to education after careers in other technical, professional areas. Case 2 audiences were the most diverse with registered educator participants from all 50 states and 58 countries. Case 3 was the only group that opened up its collaborative websites and blogs to students. The students actively participating in Case 3 activities ranged in ages from upper elementary to high school with middle school students the most frequent participants.

This study used real cases where STEM education liaisons and participants voluntarily tested the online community collaborative context. The real world aspect gives external validity to the research. Additionally, the community leaders and participants found the online intervention to be at least as attractive, engaging, and entertaining as the existing alternatives available. As Bonk (2009), O'Brien (2010), and Glanz (2010) advise, in the real world context the value of an educational intervention is secondary to being able to attract and retain the interest and enthusiasm of the desired audiences. This element of the case analysis is addressed in each of the five types of analysis by different measures. 


\subsection{Research Questions}

The analysis shows what e-collaborative tools and integration strategies were used and in what ways these tools and strategies helped the participating STEM projects achieve their goals for educator professional development. Here are the guiding research questions for each case:

1. What e-collaborative tools and strategies helped to extend and enhance the value of a STEM education project or event?

2. How did the e-collaborative tools help each case achieve some success in creating a virtual learning community?

\section{Theoretical Approach}

A professional community offers a positive and supportive climate where members agree on the educational goals and cooperate in achieving them. Interpersonal relationships within the professional community are based on shared values. Since community members are active agents in their own formation process, participation is essential. An educational community must have the active involvement of individuals who seek out this collaborative environment with one or more goals that motivate their participation.

What distinguishes a virtual community from a face-to-face community? Virtual communities are formed around a shared interest in a particular topic. Rheingold (1994) describes the potential of online social groupings based on his observations of participation in the WELL, an Internet-based bulletin board where people who had never met face to face provided socioemotional and even financial support to each other through times of crisis and celebration. Community researchers (Jones, 1997; McMillan $\&$ Chavis, 1986) propose that both co-located and dispersed groups can be communities, but members of these groups must share feelings of belonging, identity, attachment, and influence among one another. Using this criterion, virtual communities are groups of people who interact primarily through e-collaborative technologies and who have developed feelings of belonging, identity, attachment, and influence (i.e., a sense of virtual community) with each other (Blanchard, 2008).

The changes in cultural flow to a more "networked society" have been described by some researchers as a shift toward a liquid life - a fluid-like movement of people across media, material goods, local, and global spheres. Our routine interaction with digital information distinguishes our lives from previous generations (Savin-Baden, 2010; Seery, 2010). Yet our understanding of the meaning and significance of these changes is still "understudied and under theorized" (Leander, Phillips, \& Taylor, 2010).

As Bonk (2009, p. 14) says of today's educational contexts, “Online tutoring and mentoring is not just possible, it is a key aspect of education among all age groups, from primary schools to corporate training environments to those in senior citizen activity centers." Similarly, Leander and Osborne (2008) report that online teacher-facilitators position themselves and their work in multiple ways in online environments, which suggests that teachers view their role as leaders and initiators of curricular reform in ways not fully understood without further exploration of teacher roles in virtual environments.

\subsection{A Virtual Learning Community Begins with a Clearly Defined Context}

Communities of practice and online global discussion forums organize with a specific objective or end product in mind. Although there is value in the exchange of ideas, 
experiences, and opinions, face-to-face and virtual communities seek out a collaborative environment based on one or more motivating goals. Working toward a tangible goal also gives participants the opportunity to contribute to a project, event, or task that is concrete and meaningful (O’Brien \& Richey, 2010). Thus, one feature that a virtual professional community must have is an articulated purpose that may include either a previously defined or collaboratively produced set of goals and objectives and timeframe for achieving these.

The goals and objectives of a collaborative community are positioned within a context that includes a set of power structures and dynamics, organizational systems and procedures, domain knowledge systems (Islam, Kunifuji, Miura, \& Hayama, 2011), and a set of cultural and community norms. Whether in contexts that are face to face or online, efforts to facilitate collaboration are integrated into the contextual setting. Research by Leander and Osborne (2008) suggests that teacher-facilitators construct their roles as pedagogical and curricular leaders among their peers. Seery (2010) suggests that identity development in the context of education in both traditional and Web 2.0 contexts is influenced by contemporary communication technologies. Savin-Baden (2010) found that traditional rules for what is play and what is learning are challenged in the virtual setting. However, the prevailing view is that the level of online responsibility is usually connected to the work-related task that is being channelled to the collaborative website. Thus, in this instance, the role one plays in the virtual community is often similar to the role one plays with a particular group in the face-to-face context.

\subsection{Elements of Social Cognitive Theory Guide Use of E-collaborative Tools}

A basic premise of social cognitive theory (SCT) is that people learn not just through their own experiences, but also by observing the actions of others and the results of those actions (Bandura, 1986). Key constructs of SCT relevant to behavior change in STEM education in both face-to-face and online settings include observational learning, reinforcement, self-control, and self-efficacy. Some elements of behavior modification based on SCT constructs of self-control, reinforcement, and self-efficacy include goal setting, self-monitoring, and behavioral contracting. Goal setting and self-monitoring seem to be particularly useful components of effective, facilitated virtual professional communities. Successful virtual professional communities will include e-collaborative tools that support these SCT characteristics.

Self-efficacy pertains to a person's confidence in his or her ability to take action and to persist in that action despite obstacles or challenges, and it is important for influencing health behavior change efforts (Bandura, 1997). Facilitators and organizers of virtual learning communities should make deliberate efforts to increase their participants' self-efficacy using three types of strategies (Bandura, 1986):

- Setting small, incremental, and achievable goals.

- Using formalized behavioral contracting to establish goals and specify rewards.

- Monitoring and reinforcing self-monitoring by communicating beliefs and sharing reflections and ideas.

The key SCT construct of reciprocal determinism means that a person can be both an agent for change and a responder to change. Thus, to promote changes in a virtual professional community, exemplary behavior from role models and reinforcements for exemplary behavior can be used to promote the desired outcomes. 


\subsection{Integrate Strategies That Foster Individual Expression and Discussion}

In this multicase study analysis we chose particular social behavior theories and their corresponding models based on the populations involved in each of the three cases their specific behavior change concerns; the goals, objectives, and design mediation provided for the different cases; the strategies chosen to promote the behavioral change; and finally, the indices chosen to measure intervention impact (Glanz et al. 2002). Compared to other models that study behavior change at only individual or intrapersonal levels of interaction, the ecological model identifies factors that affect health behavior at multiple levels, from the individual up to the policy level (Sallis \& Owen, 2002). McLeroy et al. (1988) developed the basic working definition of the ecological model based on the idea that behavior of any individual is impacted by personal and external/environmental factors.

These factors can occur at various intersections of social, cultural, organizational, and legal activities. McLeroy et al. (1988, p.355) organized these factors at the following five levels:

1. Intrapersonal - characteristics of the individual, including knowledge, attitudes, behaviors, self-concept, skills, etc.

2. Interpersonal processes - formal and informal social networks, such as family, work groups, and friends.

3. Institutional factors - social institutions with organizational characteristics and rules for operation.

4. Community factors - relationships among organization, institutions, and informal networks within defined boundaries.

5. Public policy_-local, state, and national laws and policies.

Bausmith and Barry (2011) report that for more than a decade, professional learning communities have been touted as an effective way to build upon the knowledge and skills of experienced teachers. However, much of the evidence is based on practitioner self-reports. Although several generations of school reform have cited improvements in teacher effectiveness as key to improving student achievement, little change has occurred in the nature of professional development.

\subsection{Working Backward from a Vision of Outcomes}

The Theory of Change Model (TCM) allows an individual, organization, or group to take its vision and goals that it wants to achieve and work backward, to define what needs to be accomplished at each stage so the next step can start. The Theory of Change process moves from end goal to the beginning. The process is complete when the model identifies what needs to be set in motion and when in order for the ultimate goal to be achieved (Anderson, 2010).

The notion of readiness to change, or stage of change, has been applied in many settings (Prochaska, Redding, \& Evers, 2008). Stages of change is a heuristic model that describes a sequence of steps in successful behavior change: precontemplation (no recognition of need for or interest in change), contemplation (thinking about changing), preparation (planning for change), action (adopting new habits), and maintenance (ongoing practice of new, healthier behavior). People do not always move through the stages of change in a linear manner; they often recycle and repeat certain stages (e.g., individuals may relapse and go back to an earlier stage depending on their levels of motivation and self-efficacy). The stages of change model can be applied to help understand individual behavior as well as envisioning schools, organizations, and 
communities as being along the stages of change continuum according to their faculty, leaders', and administrations' readiness for change (Prochaska, Prochaska, \& Levesque, 2001).

\subsection{A Logical Approach to Supporting Professional Learning Communities}

The theoretical framework for this case study shows how the logic model for this case study research (see Figure 1) can be used to integrate the cognitive, psychological, sociological, and ecological models relevant to establishing and supporting virtual collaborative STEM education professional development communities. As Glanz (2010) concludes in her study of the role of behavioral science theory in the development and implementation of health-related interventions, the strongest interventions are most likely based on multiple theories that address the individual population, cultural context, and policy requirements of a given situation. Viewing each instance of theme-based initiatives to establish online virtual collaborative learning events as a form of community intervention, this mixed method case study analysis integrates the theory frameworks presented into a logic model that will guide the multiple case analyses.

\section{Logic Model for CMS Analysis}

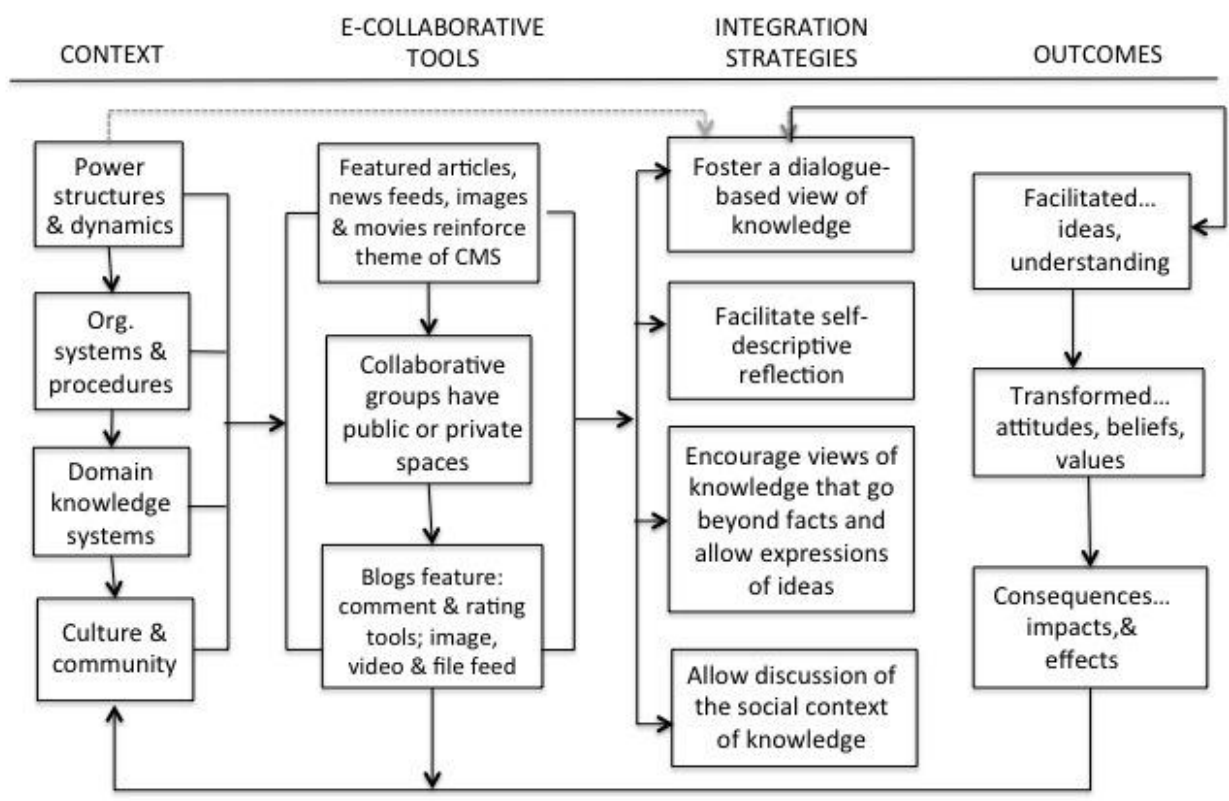

\section{Figure 1. A visual organizer showing the logic model used for CMS analysis}

The logic model for the case analysis is presented in Figure 1. With this case study focus on building STEM education collaborative learning communities, the logic model differed from previous education studies by integrating and adapting ways of integrating theory and units of practice presented in the health and occupational safety literature. This study of online communities of practice required rigorous examination of 
theory applied to a problem drawn from an authentic practice context, testing, data analysis, and iterative refinements.

Figure 1 serves as a logical roadmap to show how the research was implemented for this multicase analysis. The first task in the case study process is to define and design the relevant theory that best fits the problem and goals to be addressed along with the measures to be collected and data collection procedures. Each case presented followed the procedures outlined in the logic model.

\section{Lesson Learned About Using E-Collaborative Tools}

The examples from professional learning communities were selected because of the level of educator interest in each topic and because these topics align with national goals for improving teaching and student performance.

This multiyear qualitative study followed case study methods outlined by Green, Camilli, and Elmore (2006) and Yin (2009) to identify how theoretical expectations for virtual learning communities are expressed in tangible practices. As a longitudinal study, trends could be examined across different virtual professional community contexts and time periods. A high-level description of participants, criteria for selection of these cases, the data collection processes, and methods of analysis are presented in this section. Further details about each of these conditions are presented within the context of each case.

\subsection{Training vs. Educating: Can a Collaborative Group Help Mediate Conflicting Interests?}

Context: The Pro-Engineer online collaborative group-Case 1-provided a link to the face-to-face workshop registration, preworkshop readings, syllabus, computer-based activities, performance assessment, group articles, participating teacher materials, assignments, and postworkshop announcements, lesson plans, and copies of completed projects. Figure 2 shows a representation of the conflicting interests that teachers would have to resolve before implementing the Pro-E software and activities into their own classroom contexts. It represents the conflicts that emerged in both the face-to-face and online discussions. The primary conflicts are represented in black and point to the conflict between industry interests in having students transition from school to the workplace with knowledge of and ability to use specific "knowledge economy" tools such as Pro-E versus teachers' providing generalizable computer-aided drawing skills that can be applied with some workplace training to a broad set of careers. This tension will be addressed as part of the context discussions when planning future training-focused computer workshops that involve private sector partnerships as illustrated in the Logic Model (Figure 1).

The objective of this online collaborative and related onsite workshop was to create a new graduate course based on the computer-aided design and 3-D modeling to be taught with a multinational computer software development company. That motivated us to examine the range of issues influencing the content, goals, and anticipated outcomes for this course. Using a specific teacher professional development workshop and extended learning online graduate course provides the context to examine how the tensions between following models of instructional best practices vs. workforce training emerged in this case. The integration of computer-aided drawing and three-dimensional modeling is a popular and widely implemented teacher training topic that allows 
comparison with other course designs and has a potentially wide application to other technology education professional development communities.

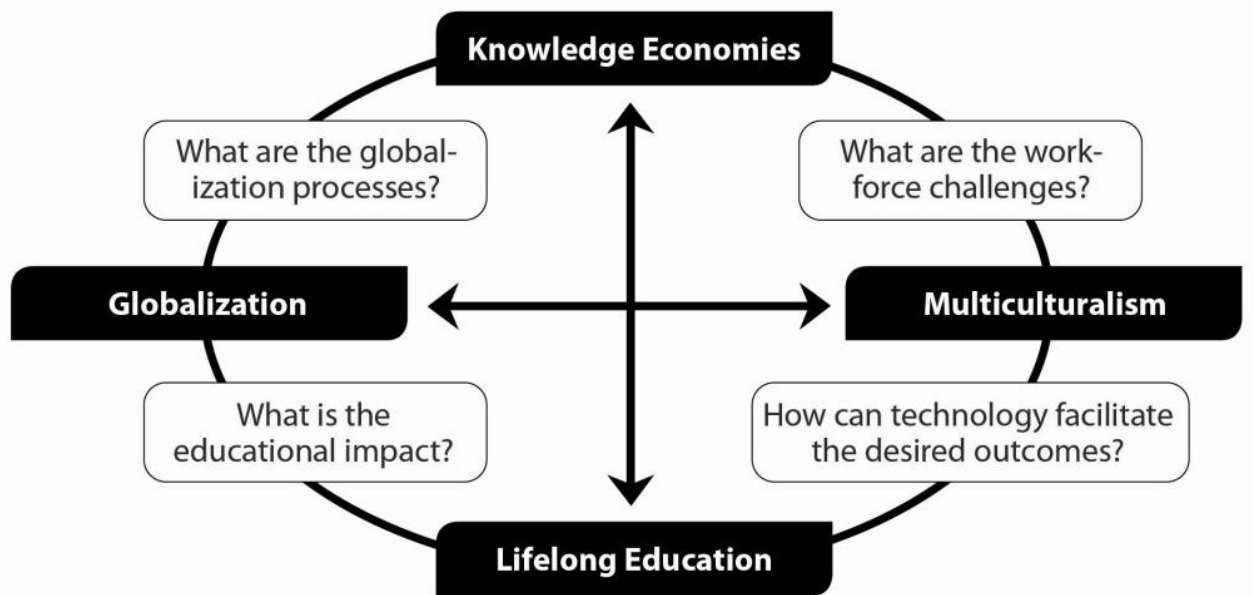

Figure 2. The relationships between the four socioeconomic trends that are examined for their impact on the instructional design of teacher professional development and classroom curriculum

These challenges emerged for this community:

- $\quad$ Structuring this course so that learners could distinguish generalizable concepts and skills to be learned from product-specific tasks and procedures.

- Integrating additional readings, activities, and self-assessment prompts to tie more directly to national, state, and district/institutional standards of learning.

- Defining the scope and sequence of the course to fit within the overall computer-aided design and technology education program.

- Designing the assignments, discussion questions, and assessment activities to help learners perceive, distinguish, and evaluate concepts, skills, and processes both within and outside the context of the software of primary focus.

- Determining to what extent the commercial partner should assist with the generic learning objectives for the course.

- Deciding what changes should be made to the course syllabus, instructional activities, classroom practices, and assessments as a result of this reflective analysis.

The Pro-E workshop and paired online collaborative group included 20 onsite participants. The data from teacher surveys, completion of computer-based exercises, observations during the face-to-face training, and postings to the online collaborative site show that teacher motivations for participating in this course varied widely, reflecting teachers' different areas of subject matter expertise and interests. Some of the teacher comments reflected their awareness of the connections between this course's technology content and its links with global economics and workforce development. Other teachers saw this course as an opportunity to expand the content and skill-based activities available in their school curriculum, regardless of subject area. 
Below are excerpts of teacher comments about their expectations for this course and motivations for pursuing this technical training. Table 1 provides a summary of the teachers' school contexts and prior experience with computer-aided design (CAD) software.

I am hoping to expand my knowledge of how technology and science mesh together. (I already understand that each needs the other to function.) And, of course, math is integral to both. Being able to help my students explore and understand the world they are living in today is important. Even more important is helping them to understand how to examine and evaluate the world of their futures as potential changes develop so they can make informed decisions. (Exploring Technology teacher, grades 6-8)

I'm hoping to get ideas of how to incorporate engineering and STEM principles into my classes. I'm very technology phobic, but with practice in "safe" settings, I increase my confidence and become a more competent educator. (home school teacher)

I would be very interested in getting certificate and graduate credit from this course. The possibilities to teach in industry also exist with this certification, as far as I know. (science teacher)

Just completed my CTE-TIS endorsement training, and I'm always looking for new and exciting ways to present curriculum materials. I also enjoy helping other staff members by providing staff in-service training. (technology academy instructor, grades 9-12)

I teach 11th and 12th grade high school drafting students ... and on the campus of [a state university satellite campus]. These students are preadmitted ... and get college credit for their four drafting classes. I hope to use $\mathrm{Pro} / \mathrm{E}$ in the students' third class, which is Mechanical Specialization Drafting \& Design. I also teach night classes at WVU-P in the drafting program. I would certainly look at the possibilities of using Pro/E in several of the classes offered. Hopefully, I will get enough info in this workshop to at least introduce students into Pro/E and visit the possibilities for future program development. (drafting teacher, grades 11-12)

Table 1. Case 1 Teacher Contexts and Prior CAD Experience

\begin{tabular}{lrr}
\hline & Number of Participants & Some Prior Experience with CAD \\
\hline Elementary School & 2 & 1 \\
Middle School & 9 & 7 \\
High School and $\quad 6$ & 5 \\
$\quad$ Community College & & \\
Home School & 2 & 2 \\
\hline TOTAL & $\mathbf{1 9}$ & $\mathbf{1 5}$ \\
\hline
\end{tabular}

E-collaborative Tools: The Pro-Engineer collaborative group was one of the first online professional collaborations hosted on NASATalk. Providing support for the ProEngineering workshop with pre- and postevent online professional development services 
was a new experience for all involved. The Pro-Engineer commercial partner had experience providing web-based video training modules and a bulletin board style website for teacher sharing. The idea of working with a hosting organization for locally based community building was at first considered to be a duplication of effort. Later it was viewed positively because teacher needs for engineering design support and professional development extended beyond the scope of Pro-Engineer software and beyond the time scheduled for the face-to-face workshop.

Several technical tools that were developed to support the Pro-Engineer training workshop with pre- and postevent professional development have been adapted and used to support subsequent virtual professional collaborative groups. These tools include the collaborative interface, which at this first stage included a brief description of the collaborative group's purpose, an area for group announcements, posting of group articles along with a rating system and comment feature, and areas to share web links and group files. The collaborative interface first used with this group was continued in the later cases with some technical enhancements.

Integration Strategies: Issues related to access and ability to use technologies were addressed in this analysis as part of the social ecology context. In this case level of access to the necessary computing technologies and abilities to use them effectively was an area of great disparity and tension for the educator participants. Many of us have encountered a similar kind of tension to the one that emerged in this collaborative community's discussions about how they would use the Pro-Engineer software. In the Case 1 context the tension was the pull between having to learn concrete, very specific tasks to become proficient using a specific software tool compared with learning general concepts and skills that could apply across a broader suite of engineering design software tools - some of which would be much easier to learn to use, install, and maintain. In Case 1 we examined the inherent conflict between:

(A) Educator goals for enduring knowledge and generalizable process skills.

(B) Global economies that desire a workforce prepared for immediate career placement.

Outcomes: Several virtual community activities to support high school-level engineering design have continued beyond this one-year virtual collaborative event. These continuing outreach activities include:

- Extended collaboration among the workshop participants and the online collaborative host.

- Continued access to the workshop materials by attendees, nonattendees, and follow-up requests for further information.

- The host site's involvement in annual student engineering competitions that emerged from the Pro-Engineer software training.

- An ongoing, but more narrowly defined online collaborative group that features student opportunities for engineering education.

\subsection{How Long Can E-Collaborative Tools Sustain a Virtual Professional Community?}

Context: The audience recruited for the Exploring the Environment - Global Climate Change (ETE-GCC) collaborative group-Case 2-surpassed more than 2,800 teachers. Most teachers registered for the original Exploring the Environment website (new funding opened up the development of six new modules focused on global climate 
change and a corresponding new website). The legacy website, which was developed more than 15 years ago, continues to be popular with teachers as judging by the number of web page views, unique users, and hits documented by the site's statistical tracking system. Table 2 provides a summary of web usage for the ETE web site.

Table 2. ETE Web Statistics

\begin{tabular}{lr}
\hline Activity for July 2011 & \\
\hline Hits & $1,012,744$ \\
Page Views & 142,726 \\
Visitors & 74,878 \\
\hline
\end{tabular}

The primary problem with this STEM project was how to engage the existing audience of registered and unregistered audiences to participate in the new website opportunities. In this case the desired outcome was to change the model of problem-based learning (PBL) from the theory presented in the legacy modules to an updated, more scientific focus for the new modules being developed. Figure 3 provides a visual summary of the PBL process that the newly designed modules follow. To grow the ETE virtual collaborative community from the existing registrants and online visitors, we designed strategies to engage this large audience of educators as contributors to the expansion and updating of the new global climate change PBL modules. As participants in the face-to-face workshop and volunteers to help with the pilot testing of new modules, the educators were invited to be part of a participatory design process (Cousins \& Whitmore, 2007).

The goals for this collaborative group match well with the construct of stage of change, which is a key element of the Theory of Change Model. This construct assesses an individual's readiness to act on a new, healthier behavior and provides strategies or processes of change to guide the individual through the stages of change to action and maintenance. In this case the stages of change being promoted relate to the processes and resource tools teachers use to implement problem-based learning in their classroom teaching. This case used the Theory of Change Model to develop an approach to address the challenges associated with trying to grow this virtual learning community. The TCM of behavior change is a good match for the ETE-GCC project because the TCM proposes that people are at different stages of readiness to adopt changes in their existing teaching behaviors and practices (Prochaska, Redding, \& Evers, 2008). Using the TCM allowed the researchers to begin with the revised vision for the updated PBL process and work backward, to define what needs to be accomplished at each stage so the next step can be begun. The process is complete when the model identifies what needs to be set in motion and when in order for the ultimate goal to be achieved.

E-collaborative Tools: The visual organizer presented in Figure 3 provides an overview of the updated PBL problem-solving processes for the new modules (initially pilot tested in summer 2011). It also highlights several key differences between the legacy and updated PBL modules. Two key ones were that (a) the updated version involved integrated use of technology tools, startup investigations to offer skill building, and guided inquiry for those who needed scaffolding to get started on their investigations, and (b) the updated version identified areas where electronic question prompts and opportunities for reflective sharing, peer review, and revision are suggested as techniques that have been shown to increase student learning on a given PBL and enhance transfer of problem-solving skills that apply to future learning. 


\section{Designing Cognitive Scaffolds for Web-based Problem-based Learning}
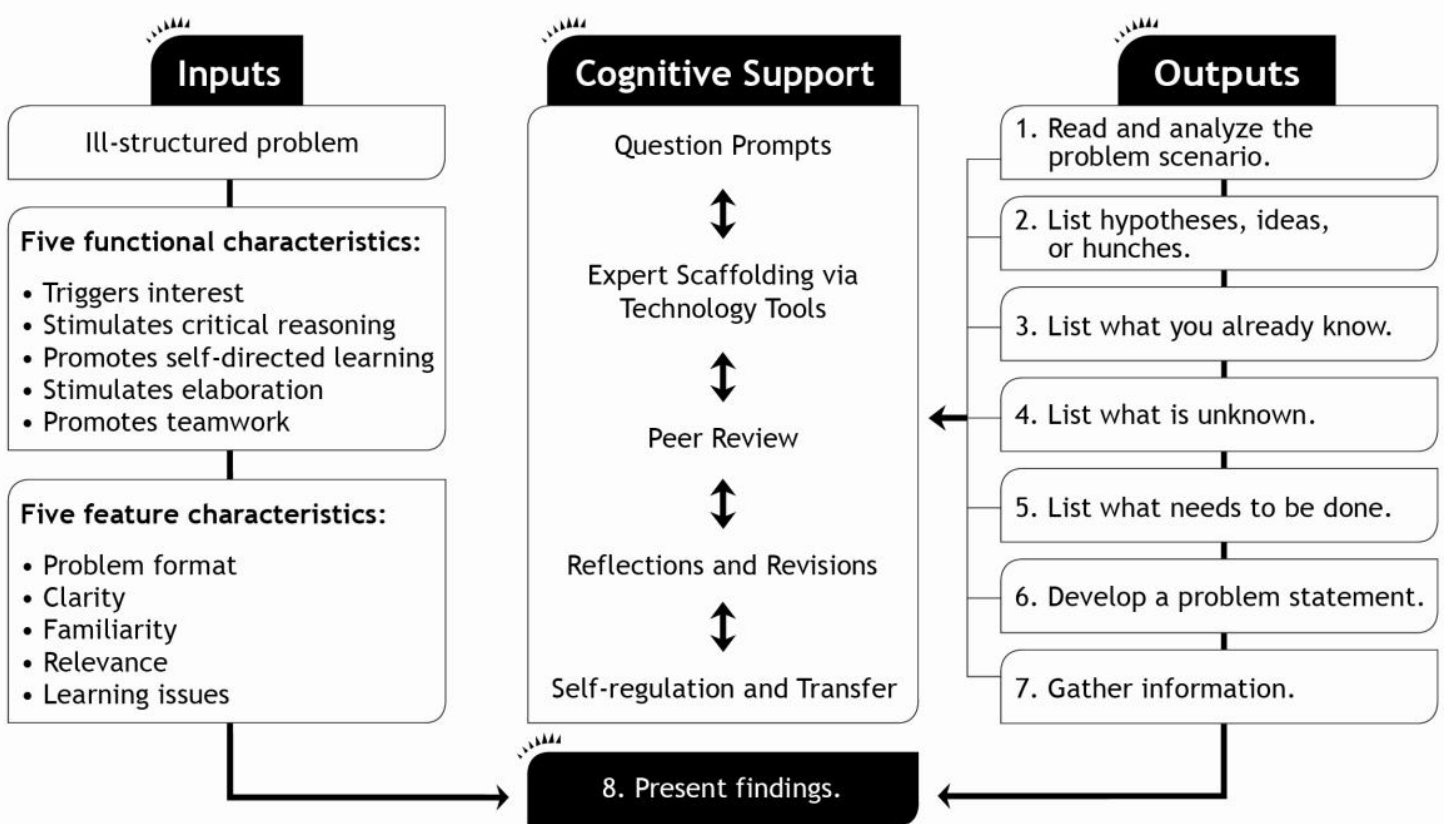

Figure 3. The updated problem-solving processes in the Exploring the Environment website

A new feature added to support the Exploring the Environment community was an embedded blog function tied into the collaborative. We used this function to highlight updates to the ETE website; inform community members about webinar, workshop, and conference opportunities; and highlight new data tools and online resources available to support their implementation of the new PBL process. Figure 4 shows what characteristics participants at the 2011 annual meeting of the National Science Teachers Association said in a survey were most important to them in an online collaborative community. By linking a wiki site to the Joomla-based collaborative for the live face-toface event, the researchers were able to compare usability functions across the different media and see what was easiest to use.

Integration Strategies: All of these changes to the problem-solving process and instructional approach to PBL were based on research guidelines that were published after the ETE legacy modules were first developed. While many educators still come to Exploring the Environment websites and, we believe, continue to use the legacy modules, we looked for ways to apply the TCM model to suggest ways that teachers who are experienced and skilled at integrating PBL into their classroom instruction would consider changes in stages that would integrate components of the updated problemsolving processes. We integrated an online collaborative called ETE Global Climate Change to foster a dialogue-based introduction to the changes from the previous to the 
new PBL model. The collaborative group is open to the public and links to this virtual professional community are embedded in each of the legacy and new PBL pages.

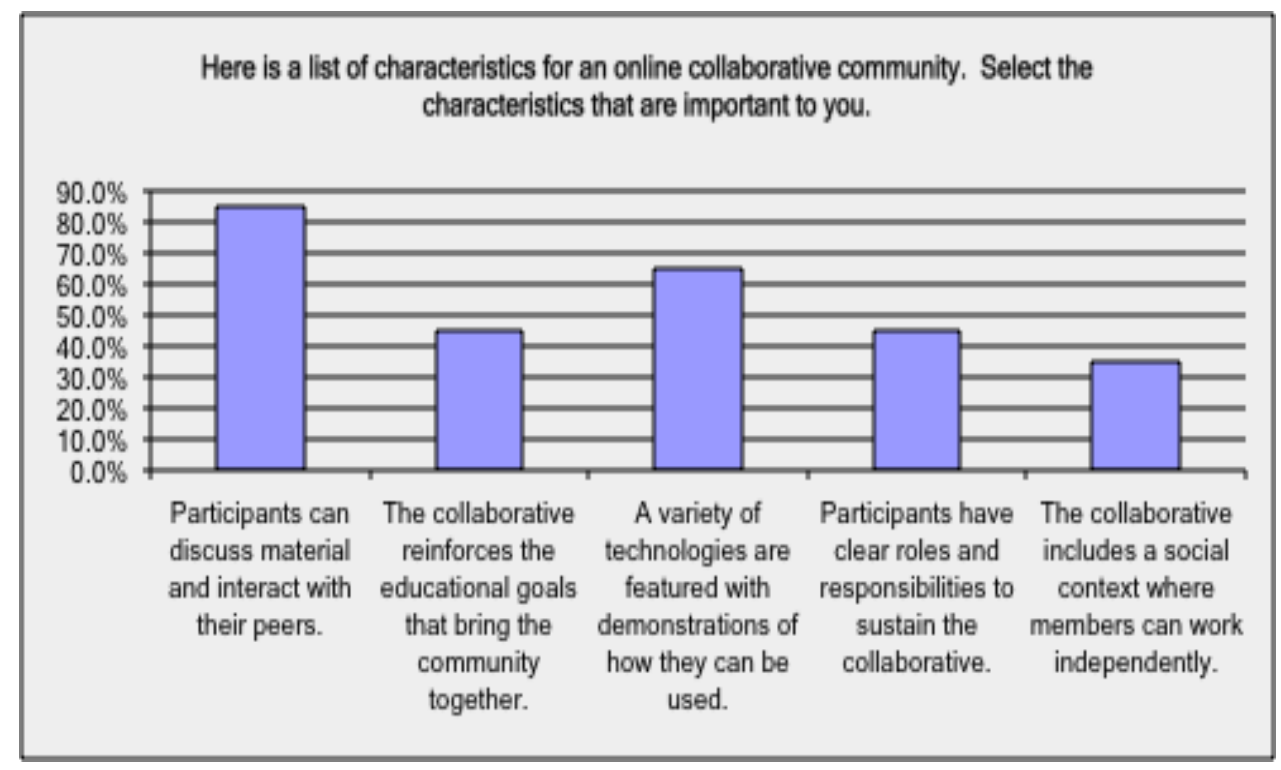

Figure 4. Educator ratings of characteristics for an online collaborative community

Within a year of its establishment on May 12, 2010, the ETE-Global Climate Change collaborative site had created 20 unique blogs. Additional data sources included NASA activity summary data forms, online usage statistics, online activity analyses (including comments, ratings, postings by individuals outside the project staff), survey data (such as the NSTA workshop survey), and observations and additional data collected from face-to-face workshops and external scientist and educator reviews of prototype versions of the updated PBL modules. The ETE PBL online collaborative site used blog postings, links to webcast opportunities, and featured web links, and it hosted a face-toface workshop at the 2011 National Science Teachers Association conference in March to engage science educators in the process to update PBL implementations.

Anticipating Outcomes: Based on input gathered at NSTA, we learned that most educators were already members of one or more virtual learning communities - and a wide range it was they joined according to their professional and personal interests, including NSTA Weblinks, Exxon Mobile Teacher Academy, Sally Ride Academy Net Links, Facebook, Internal Education Site, GLOBE Science Network, GLOBE_Program.Net, GirlsRISE.net, Twitter, Edmodo, Linked-In, and Catalyst. We asked NSTA attendees to rate their prior experience using an online virtual collaborative group to enhance teaching and professional development. Most respondents (76\%) reported prior experiences using VLC to be important or moderately important, 20 percent reported that it was of little importance, and the remaining 5 percent rated their VLC experience as very important.

\subsection{A Suite of Robotics Collaborative Websites and Blogs}

Context: The greatest challenge for starting up and supporting the virtual collaborative community in Case 3 was to find ways to offer a variety of online venues that could 
interrelate and avoid duplication, yet accommodate the diverse needs of this highly active community that includes school groups, teachers, youth groups (like Girl Scouts and community-based robotics clubs), and professional coaches and commercial vendors. There was a spirit of fun, enthusiasm, and sense of immediacy to a few of the robotics collaborative group and blog discussions, which brought students into the online collaborative communities and kept them actively involved. Students started out posting online comments, but they moved to writing their own blogs and setting up their own Facebook groups to share photos and videos of their accomplishments in the WaterBotics workshop they attended. A major robotics competition featured in the LEGO online communities, FIRST LEGO League (FLL), helps bridge the gap between the technological and natural world as students research and propose real solutions to authentic problems. For instance, a Girl Scouts FLL team helped design a prosthetic to help a little girl born without a hand to be able to write.

Table 3. Characteristics and Functions of Social Networks

\begin{tabular}{|c|c|}
\hline Concepts & Definitions \\
\hline \multicolumn{2}{|c|}{ Structural characteristics of social networks: } \\
\hline Reciprocity & $\begin{array}{l}\text { Extent to which resources and support are both given and received in } \\
\text { a relationship }\end{array}$ \\
\hline Intensity & $\begin{array}{l}\text { Extent to which social relationships offer emotional closeness or } \\
\text { strength }\end{array}$ \\
\hline Complexity & Extent to which social relationships serve many functions \\
\hline Formality & $\begin{array}{l}\text { Extent to which social relationships exist in the context of } \\
\text { organizational or institutional roles }\end{array}$ \\
\hline Density & Extent to which network members know and interact with each other \\
\hline Homogeneity & Extent to which network members are demographically similar \\
\hline Geographic & $\begin{array}{l}\text { Extent to which network members live in close proximity to focal } \\
\text { dispersion person }\end{array}$ \\
\hline Directionality & $\begin{array}{l}\text { Extent to which members of the dyad share equal power and } \\
\text { influence }\end{array}$ \\
\hline \multicolumn{2}{|c|}{ Functions of social networks: } \\
\hline$\overline{\text { Social capital }}$ & Resources characterized by norms of reciprocity and social trust \\
\hline Social influence & $\begin{array}{l}\text { Process by which thoughts and actions are changed by actions of } \\
\text { others }\end{array}$ \\
\hline Social undermining & $\begin{array}{l}\text { Process by which others express negative affect or criticism or hinder } \\
\text { one's attainment of goals }\end{array}$ \\
\hline Companionship & Sharing leisure or other activities with network members \\
\hline Social support & $\begin{array}{l}\text { Aid and assistance exchanged through social relationships and } \\
\text { interpersonal transactions }\end{array}$ \\
\hline \multicolumn{2}{|l|}{ Types of social support: } \\
\hline Emotional support & Expressions of empathy, love, trust, and caring \\
\hline Instrumental support & Tangible aid and services \\
\hline $\begin{array}{l}\text { Informational } \\
\text { support }\end{array}$ & Advice, suggestions, and information \\
\hline Appraisal support & Information that is useful for self-evaluation \\
\hline
\end{tabular}

Adapted from Heaney and Israel (2008) 
E-collaborative Tools: A suite of blogs and online collaborative groups were set up on the NASATalk website to support the variety of robotics activities under way at the Center for Educational Technologies and with external partners. Some of these blogs and collaborative groups did not require registration or a subscription. For example, the Robotics and Engineering ePDN Collaborative and Blog was set up as a public forum in partnership with other NASA-funded organizations working on projects with similar STEM education goals. This group allowed for continued collaboration after the completion of the NASA-funded ePDN Robotics online course. The ePDN robotics course actually had two collaborative groups and associated blogs-the one mentioned here was open to the public; the other was created as a private, invitation-only site to allow teachers to share artifacts (including videos of students doing robotics-related activities) at school.

Integration Strategies: The robotics online collaborative groups and blogs that involved students and robotics team coaches demonstrated more social interaction and social characteristics than the other virtual communities. Because of the greater frequencies of these expressions, use of the social cognitive theory (SCT) (as outlined in the theoretical framework section) was a quite appropriate model to guide analysis of this case. A taxonomy of social support characteristics and function can be used to identify the types of positive social support exhibited in the robotics collaborative web pages and blogs. Characteristics and functions highlighted in italics in Table 3 were observed in the VLC interactions.

E-collaborative Tools: The data sources for this case included online surveys, blog postings, collaborative articles, announcements, sharing of files, web links, programming tips and code, and three separate collaborative applications. Below is an example of robotics collaborative interaction between student and teacher, which provides a good example of a type of "appraisal support" and can be internalized by the student as a positive piece of information for their self-evaluation.

Student posting: Our ROV [remotely operated vehicle] was extremely successful in the Figure 8 Challenge; our tight turns and speedy, hydrodynamic design triumphed once again. We also added a third motor today so we could submerge the ROV. We had to remove some of the foam and we rebuilt the body so there was a hole in the middle for the propeller. We ran the program for the horizontal motors parallel to the program for the vertical motor. We are controlling the direction and speed of the vertical motor with a level [attached] to a rotation sensor. The design resembles a frog, so I have been referring to the ROV as Kermit. It is going to be difficult to control the ROV for this challenge, but I think with a little practice we will get a feel for the new controls.

Teacher comment posted in reply to student posting: I am so impressed with how well your team designed your robot to work so well. I didn't know about the rotation sensor speed / direction control capabilities when I went into the challenge, and I have to say my team failed at this one. Our robot either spun out of control or flipped every time we turned on the third big propeller on the bottom. You can read more details on my Day 4 WaterBotics at: LEGOMINDSTORMS NXT Robotics blog at: http://www.nasatalk.com.

Note: The student posting has a 7 out of 7 star rating, and the descriptor, Excellent, which shows an additional SCT action of encouragement and support for this student's blog posting. 
When the Robotics collaborative groups were organized, the NASATalk online collaborative project had been under way for two years. By the spring of 2010, it had established some procedures to help those requesting new collaborative sites get started by thinking through some of the goals, objectives, target audiences, and level of activity/postings they hoped to achieve on their site. Of interest to this case study was that four different individuals submitted requests to set up NXT LEGO robotics collaborative groups on NASATalk. Several areas differ and for obvious reasons would have an impact on the level of commitment and possible outcomes for the collaborative sites. These areas include institutional affiliation and the length of time the collaborative has been set up and promoted.

Outcomes: Among the three cases reported on in this study, the robotics collaborative incorporated the most SCT strategies. This was the newest of the three VLCs, and it was the most active. It also was the only one to include students. The robotics VLC also included teachers, parents, coaches, and members of the private sector technical community. We continue to learn how to adapt our Internet tools to better serve this dynamic and youthful audience.

\section{Applicability of the Logic Model for CMS Analysis}

The findings and results for each of the cases are summarized in a cross-case analysis that responds to each of the research questions. The logic model provided the organizational structure for the three case analyses. The discussion concludes with a review across all of the cases to summarize how this study of three NASATalk VLC cases improves our understanding of how to design VLC technology features to enhance collaboration and scaffold learning. The insights gained from these three cases also identify design strategies that can enhance the evaluation of virtual learning communities.

\subsection{Tools and Strategies That Help to Build, Support, Manage, and Sustain a VLC}

Some of the lessons learned from Case 1 sound obvious today, but in 2009 when setting up this first collaborative community, these were new undertakings. The Joomla open source software system did not offer a template with the integrated suite of features that the researchers wanted for an online collaborative group. A new collaborative template was created with features that allowed participants to do the following: publish articles with images and links and formatting capabilities typically found on any web page; post announcements; upload files (of a wide array of file types); cite one or many web links with descriptive annotations. Creating a collaborative template that could support these features marked a milestone in being able to build, support, manage, and sustain a VLC. The design team was pleased to learn that educators found the process of uploading their lesson plans and assessment rubrics easier to do on the NASATalk collaborative than on the Pro-Engineer teacher pages.

Having the technology tool in place and functioning, however, gave the VLC a foundation, but without a partnering group, the facility was set up, but the rooms were empty. When the opportunity was presented to host a Pro-Engineer course at our facility, we saw this as an ideal test case. Hosting the Pro-Engineer training as an online collaborative group was an event well-suited to starting a VLC because this software is complex and integrates several tools. Pro-Engineer offers online training, and a collaborative group on a separate site allowed educators taking the training to share feedback about the training options and among a group having shared experiences and 
interests. The Pro-Engineer training workshop was also a good test case because it was new to most of the CAD instructors, who had to learn together how to incorporate this new tool into their instructional setting. The fact that the NASATalk site would let them upload lesson plans, assessment rubrics, and class projects to share with their peers was also a valuable component of this program.

Each of these characteristics could be applied to the other cases. Cases 2 and 3 were able to build on the tools developed for Case 1 and expand with requests for new features based on the needs of their different content focuses and audiences. The ETE collaborative included two embedded blogs, which allowed further targeting of the messages for this community. The robotics VLC was able to upload NXT or other robotics programming files to share among its community groups of coaches and competition teams.

\subsection{Tools and Strategies That Support Complex Problem Solving in a VLC}

The ETE Global Climate Change collaborative was publicly accessible on the Internet as a NASATalk collaborative web group. It was also a featured link embedded as part of the footer on each of the Exploring the Environment web pages. By inserting itself into the existing modules, the ETE collaborative was able to recruit members for the updated problem-solving process from within the existing PBL process. The updated PBL process presented in Figure 3 was designed to contrast with the model featured on the Teacher Pages of the legacy website. Participants in the ETE Global Climate Change collaborative were, as Shute (2008) suggests, invited to share in the process of updating the modules and teacher pages for the new modules. Teachers participated in pilot testing that was promoted via the virtual learning community. They also provided feedback on the new modules at the 2011 NSTA research symposium workshop, which resulted in the integration of wiki pages to allow teachers an easier interface for uploading their comments and requests for additional classroom options for activities.

\subsection{Tools and Strategies That Facilitate Peer Interactions and Collaboration in a VLC}

Ease of access and use are priorities for the collaborative websites and blogs. As new communities, like the robotics group, came to use the site, the design and research team looked for ways to make the site available on mobile devices and social media tools. The article and blog rating tool was used by robotics mentors to encourage communication in the collaborative by student and youth mentors. The notifications system helped members of collaborative groups receive e-mail or mobile device notifications when new articles or comments were posted in their areas of interest. With integration of social media links, the collaborative groups started to share topical playlists in YouTube. While the site host was concerned about the privacy issues of students starting their own Facebook group to share their images, their desire to share what they were learning showed the enthusiasm that the students had for what they were doing with robotics.

\subsection{Challenges to Building, Supporting, Managing, and Sustaining a VLC}

A condition associated with this research that rings true with research on science education by Osborne and Barker (2007) is that "in this age of national standards and outcomes followed by high-stakes achievement tests, teachers ... are ... more frequently expected to develop the local, concrete, and connected expressions of national or state 
expectations. This is important, for it is what makes the abstract list of national standards or outcomes relevant and connected. It is what makes the mandated curriculum teachable and educational reform, described at the policy level, actualized in the classroom" (p. 3).

Applying the findings from Schwier (2010) to the research issues presented above, we present guidelines to help science educators design online environments to enhance integration of their coursework, training, or products. Social ecological models examine the multiple levels of influence (such as individual, interpersonal, organizational, community, and public policy) on human behavior within the context of their social environment. From the social ecology theory perspective, behaviors shape and are reciprocally shaped by the social environment (McLeroy, Bibearu, Steckler, \& Glanz, 1988). Theory-based models of behavior change are used because they help to explain the dynamics of human behavior, such as why individuals choose to follow or not follow particular procedures, methods, practices, and/or recommendations. Behavior change models help to explain social structures, barriers, or support mechanisms that can significantly influence whether a behavior change can occur.

\section{Conclusion and Recommendations for Future Directions}

The lessons we learned from these three cases show that virtual learning communities can be effective means to facilitate peer interactions and collaborations, but each of these cases demonstrate that improvements can be made in future offerings through effective application of the theory framework to iterative goal setting and data collection with permission of the collaborative being studied. As the researcher develops a collaborative relationship with the population involved, the researcher/practitioner partnership can lead to further study of the culture, behavior, and outcomes of future virtual learning communities.

\section{References}

1. Allen, W. (2011). Theory of Change and Logic Models. Accessed 20 August 2011 at: http://learningforsustainability.net/evaluation/theoryofchange.php.

2. Anderson, A. (2010). The Community Builders Approach to Theory of Change: A Practical Guide to Theory Development. The Aspen Institute Roundtable on Community Change, NY, NY. Downloaded August 26, 2011 from: www.theoryofchange.org.

3. Bandura, A. (1986). Social Foundations of Thought and Action: A Social Cognitive Theory. Englewood Cliffs, NJ: Prentice-Hall.

4. Bandura, A. (1997). Self-Efficacy: The Exercise of Control. New York: WH Freeman.

5. Bausmith, J.M., \& Barry, C. (2011). Revisiting Professional Learning Communities to Increase College Readiness: The Importance of Pedagogical Content Knowledge. Educational Researcher, 40(4), 175-178.

6. Blanchard, A.L. (2008). Definition, Antecedents, and Outcomes of Successful Virtual Communities. University of North Carolina, Charlotte, USA: IGI Global. $\begin{array}{lllll}\text { Downloaded } & 29 & \text { Nov } 2011 & \text { from }\end{array}$ global.com/viewtitlesample.aspx?id=12415.

7. Bonk, C.J. (2009). The world is open: How Web technology is revolutionizing education. Jossey-Bass. 
8. Cheuk, B., \& Dervin, B. (2011). Leadership 2.0 in action: A journey from knowledge management to "knowledging." Knowledge Management \& ELearning: An International Journal, .3(2), 119-137.

9. Cousins, J. B., \& Whitmore, E. (1998, 2007). Framing participatory evaluation. New Directions for Evaluation, 89, 114.

10. Eynon, R., Fry, J., \& Schroeder, R. (2008). The ethics of Internet research (p. 2341). In N. Fielding, R. M. Lee, \& G. Blank (eds.), Online Research Methods. Sage: Los Angeles.

11. Glanz, K., \& Bishop, D.B. (2010). The Role of Behavioral Science Theory in Development and Implementation of Public Health Interventions. Annual review of public health, 31, 399-418.

12. Green, J.L., Camilli, G., \& Elmore, P.B. (Eds.). (2006). Handbook of complementary methods in education research. Washington, DC: American Educational Research Association.

13. Heaney, C.A., \& Israel, B.A. (2008). Social Networks and Social Support. In K. Glanz, Lewis, F.M., \& Rimer, B.K. (Eds.), Health behavior and health education: Theory, research and practice (pp.97-121). San Francisco: Jossey-Bass.

14. Howard, B., \& Tomei, L. (2010). Emerging educational technologies and science education: A multifaceted research approach. In L. Tomei (Ed.), ICTs for modern educational and instructional advancement: New approaches to teaching. Hershey, PA: IGI Global.

15. Islam, M.S., Kunifuji, S., Miura, M., \& Hayama, T. (2011). Knowledge Management \& E-Learning: An International Journal, 3(3), 375-398.

16. Jones, Q. (1997). Virtual communities, virtual settlements and cyber-archaeology. Journal of Computer Mediated Communication, 3(3).

17. King, J.A. (1998). Making sense of participatory evaluation. New Directions for Evaluation, 80, 57-67.

18. Klauer, K.J., \& Phye, G.D. (2008). Inductive reasoning: A training approach. Review of Educational Research, 78(1), 85-123.

19. Lawless, K.A., \& Pellegrino, J. W. (2007). Professional development in integrating technology into teaching and learning: Knowns, unknowns, and ways to pursue better questions and answers. Review of Educational Research, 77(4), 575-614.

20. Leander, K.M., Phillips, N.C., \& Taylor, K.H. (2010). The changing social spaces of learning: Mapping new mobilities. Review of Research in Education, 34, 329394.

21. Leander, K.M., \& Osborne, M.D. (2008). Complex positioning: teachers as agents of curricular and pedagogical reform. Journal of Curriculum Studies, 40(1), 23-46.

22. McAlister, A.L., Perry, C.L., Parcel, G.S. (2008). How individuals, environments and health behaviors interact: social cognitive theory. In Glanz, K., Rimer, B.K., Viswanath, K. (eds.), Health Behavior and Health Education: Theory, Research, and Practice. San Francisco: Jossey-Bass. 4th ed., pp. 167-88.

23. McLeroy, K., Bibearu, D., Steckler, A., \& Glanz, K. (1988). An Ecological Perspective on Health Promotion. Health Education Quarterly 13(4), 351-377.

24. McMillan, D.W., \& Chavis, D.M. (1986). Sense of community: A definition and theory. Journal of Community Psychology, 14(1), 6-23.

25. O'Brien, M., \& C. Richey. (2010). Knowledge Networking for Family Planning: The Potential for Virtual Communities of Practice to Move Forward the Global 
Reproductive Health Agenda. Knowledge Management \& E-Learning: An International Journal, 2 (2), 109-121.

26. Osborne, M.D., \& Barker, H.B. (accepted). Curriculum development: Local teacher-based curriculum development. In A. Luke \& P. D. Pearson (Eds.), International Encyclopedia of Education. New York: Elsevier.

27. Pea, R. D. (1985). Beyond amplification: Using the computer to reorganize mental functioning. Educational Psychologist, 20(4), 167-182.

28. Porter, A.C. (2006). Curriculum assessment. In J.L. Green (Ed.), Handbook of Complementary Methods in Education Research. Washington, DC: American Educational Research Association.

29. Prochaska, J.M., Prochaska, J.O., \& Levesque, D.A. (2001). A transtheoretical approach to changing organizations. Adm. Policy Ment. Health 28,247-261.

30. Prochaska, J.O., Redding, C.A, \& Evers, K.E. (2008). The transtheoretical model and stages of change. In K. Glanz, Lewis, F.M., \& Rimer, B.K. (Eds.), Health behavior and health education: Theory, research and practice (pp.97-121). San Francisco: Jossey-Bass.

31. Rheingold, H. (1994). The Virtual Community: Finding Connection in a Computerised World. London: Secker \& Warburg.

32. Ruberg, L., Calinger, M., \& Howard, B. (2009). Evaluating educational technologies: Historical milestones. In L.A. Tomei (Ed.), Designing instruction for the traditional, adult, and distance learner: A new engine for technology-based teaching. Hershey, PA: IGI Global.

33. Ruberg, L., Chen, C.-H., \& Martin, J. (2007). NASA Explorer Schools project evaluation: Summer 2003 to spring 2006. Center for Educational Technologies, http://www.cet.edu/?cat=publications\&page $=35$.

34. Sallis, J., \& Owen, N. (2002). Ecological Models of Health Behavior. In K. Glanz, Lewis, F.M., \& Rimer, B.K. (Eds.), Health behavior and health education: Theory, research and practice. San Francisco: Jossey-Bass.

35. Savin-Baden, M. (2010). Changelings and shape shifters? Identity play and pedagogical positioning of staff in immersive virtual worlds. London Review of Education, 8(1), 25-38.

36. Schwier, R.A. (2010). Comparing learning communities in formal, non-formal, and informal learning environments: Cattle drives, watering holes, murders of crows. Association for Educational Communication and Technology (AECT) Distance Learning Symposium. Downloaded from http://www.aect.org/Events/symposia/sessions.asp?clientid.

37. Seery, A. (2010). Education, the formation of self and the world of Web 2.0. London Review of Education, 8(1), 63-73.

38. Shute, V.J. (2008). Focus on formative feedback. Review of Educational Research, 78(1), 153-189.

39. Smith, M.L. (2006). Multiple methodology in education research. In Handbook of complementary methods in education research. Washington, DC: American Educational Research Association.

40. Spring, J. (2008). Research on globalization and education. Review of Educational Research, 78(2), 330-363.

41. Yin, R.K. (2009). Case study research: design and methods. Thousand Oaks, CA, Sage Publications. 